\title{
Spectrophotometric Data in Human Immunodeficiency Virus (HIV)-Antiretroviral Drug Coated Blood Interactions
}

\author{
Okwuchukwu Ani' ${ }^{1}$, Adaeze Ani' ${ }^{2}$, Jeremiah Chukwuneke ${ }^{3}$ \\ ${ }^{1}$ Department of Mechanical and Production Engineering, Enugu State University of Science and Technology, \\ Agbani, Nigeria \\ ${ }^{2}$ College of Medical Sciences, University of Maiduguri, Maiduguri, Nigeria \\ ${ }^{3}$ Department of Mechanical Engineering, Nnamdi Azikiwe University, Awka, Nigeria \\ Email: okwyenoch@yahoo.com, adaezenwezoku@yahoo.com, jl.chukwuneke@unizik.edu.ng
}

Received 17 July 2015; accepted 18 August 2015; published 21 August 2015

Copyright @ 2015 by authors and Scientific Research Publishing Inc.

This work is licensed under the Creative Commons Attribution International License (CC BY). http://creativecommons.org/licenses/by/4.0/

(c) (i) Open Access

\section{Abstract}

The spectrophotometric data in the interactions between the Human immunodeficiency virus (HIV) and blood cells treated with antiretroviral drug were collected to be used to show the effects of antiretroviral drugs on the absorbance characteristics of HIV infected and uninfected blood. The methodology involved the serial dilution of the five different antiretroviral drugs (two HAART/FDC and three single drugs) and the subsequent incubation with the blood samples collected from ten HIV infected persons who had not yet commenced treatment with the antiretroviral drugs, ten HIV infected persons who had already commenced treatment with the antiretroviral drugs, and ten HIV negative persons, for the absorbance measurements using a digital Ultraviolet Visible MetaSpecAE1405031Pro Spectrophotometer. The peak absorbance data for various interacting systems were measured. These were used to show that the antiretroviral drug had the effect of increasing the peak absorbance values of both the uninfected and infected blood components, i.e., the drugs were made able to increase the light absorption capacity of the blood cells. The use of the findings of this work in drug design may be expected to yield good results.

\section{Keywords}

Absorbance, Human Immunodeficiency Virus, Antiretroviral Drug, Blood Components, Wavelength 


\section{Introduction}

The HIV/AIDS cases have hitherto been managed clinically with the discovery and administration of highly active anti-retroviral therapy (HAART). But these anti-retroviral drugs are heavily attacked and resisted by the HIV in the human system because they are DNA-based while the HIV is RNA-based. Hence, the ineffectiveness and failure of HAART are as a result of the ability and capacity of HIV to develop resistance to the administered anti-retroviral drugs even when the combination therapy is for the HIV patient. The discovery and application of highly active anti-retroviral therapy (HAART) to suppress HIV have revolutionized the clinical management of HIV/AIDS cases. The HIV, however, has the capacity to develop resistance to the antiretroviral drugs and this phenomenon has turned out to be a significant cause of failure of HAART [1]. HIV, which is a rapidly mutating RNA-based virus, lacks the ability to checkmate the possible genetic mutations that can occur during replication. Hence, this rapid genetic variation has become the major factor for which this menace has consistently defiled clinical solutions.

The increasing rate of HIV infection globally is blamed on the ineffectiveness of some available antiretroviral therapy to block or resist perfectly this virus from invading the uninfected white blood cells. The mechanism by which drugs can block the virus seems weak and hence it becomes necessary to study the interaction between the HIV and the drug-coated white blood cells. The problem of formulating drugs that can summarily eliminate HIV remains a challenge. The question arises as to how effective the available antiretroviral drugs are. The answer to such question may be found by studying surface effects in HIV-drug interactions.

There are several classes of drugs, which are usually used in combination, to treat HIV infection. Use of these drugs in combination can be termed as anti-retroviral therapy (ART), combination anti-retroviral therapy (cART) or highly active anti-retroviral therapy (HAART). Anti-retroviral (ARV) drugs are broadly classified by the phase of the retrovirus life-cycle that the drug inhibits. Typical combinations include 2 NRTIs as a "backbone" along with 1 NNRTI or 1 PI as a "base" [2].

Since some of the drugs act as blockers, the blocking will be effective if the drug completely coats the cells. The extent of the cell surface that is coated is important.

We intend to use the concept of absorbance to address this issue. Achebe and Omenyi [3] have shown that absorbance is a surface phenomenon. They showed that the peak absorbance of the surface of each blood component was reduced by the presence of the virus. The question now arises is to what extent the peak absorbance of the surface of a given HIV infected blood component is changed by the administration of the anti retroviral drugs.

\section{Methodology}

\subsection{Sample Collection}

The popular and commonly used unexpired Antiretroviral drugs (three single tablets and two HAART), from the University of Nigeria Teaching Hospital (UNTH) APIN CENTRE PEPFAR, Ituku-Ozalla, Enugu State were collected (see Figure 1). Table 1 shows the details of the five different antiretroviral drugs used in the study. Drugs 1 and 2 are both Highly Active Antiretroviral Therapy (HAART) as well as Fixed Dose Combination (FDC), while drugs 3, 4 and 5 are single antiretroviral drugs. Drugs 1, 3 and 5 are administered to HIV patients twice daily while drugs 2 and 4 are taken once a day. It is worthy to note that all the antiretroviral drugs used were not expired during the period of the experiments.

Blood samples were collected from Nnamdi Azikiwe University Teaching Hospital (NAUTH) Nnewi and Anambra State Teaching Hospital, Amaku as follows:

- From ten HIV infected persons who were not yet on HIV drugs;

- From ten infected persons that had already commenced treatment with antiretroviral drugs;

- From ten HIV negative persons.

Altogether, a total of thirty samples from different individuals were collected and screened to determine the infection status and stored in anticoagulant test tubes and ice packs to ensure the freshness and to avoid the samples becoming lysed. The samples were thereafter stored in a refrigerator for proper preservation.

\subsection{Sample Preparation}

The drugs passed through serial dilution at Tahilah Diagnostic Laboratories, Awka, in order to get the right 


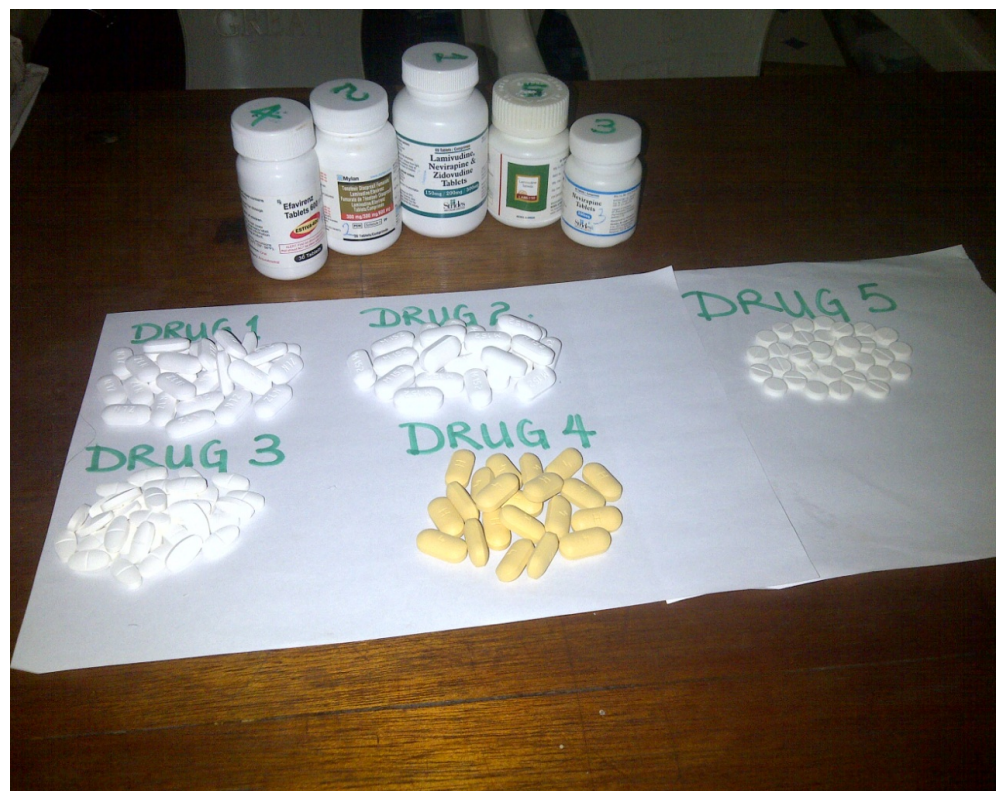

Figure 1. The tablets of the five different antiretroviral drugs used.

Table 1. The details of the five different Antiretroviral Drugs used in the Study.

\begin{tabular}{|c|c|c|c|c|c|c|}
\hline $\begin{array}{c}\text { Drug } \\
\text { Number }\end{array}$ & Tablets & Abbreviation & Size & $\begin{array}{c}\text { Batch } \\
\text { Number }\end{array}$ & $\begin{array}{c}\text { Expiration } \\
\text { Date }\end{array}$ & $\begin{array}{l}\text { Pharmaceutical } \\
\text { Company }\end{array}$ \\
\hline 1 & $\begin{array}{c}\text { Lamivudine, } \\
\text { Nevirapine \& Zidovudine }\end{array}$ & $3 \mathrm{TC}+\mathrm{NVP}+\mathrm{ZDV}$ & $150 \mathrm{mg} / 200 \mathrm{mg} / 300 \mathrm{mg}$ & 7220929 & $01 / 2016$ & Strides Arcolab Limited \\
\hline 2 & $\begin{array}{c}\text { Tenofovir, } \\
\text { Lamivudine \& Efavirenz }\end{array}$ & $\mathrm{TDF}+3 \mathrm{TC}+\mathrm{EFV}$ & $300 \mathrm{mg} / 300 \mathrm{mg} / 600 \mathrm{mg}$ & 3018522 & $09 / 2015$ & $\begin{array}{c}\text { Mylan Laboratories } \\
\text { Limited }\end{array}$ \\
\hline 3 & Nevirapine & NVP & $200 \mathrm{mg}$ & 7216348 & $04 / 2015$ & Strides Arcolab Limited \\
\hline 4 & Efavirenz & EFV & $600 \mathrm{mg}$ & E121035A & $07 / 2015$ & $\begin{array}{l}\text { HETERO LABS } \\
\text { LIMITED }\end{array}$ \\
\hline 5 & Lamivudine & $3 \mathrm{TC}$ & $150 \mathrm{mg}$ & LEX - 023 & $04 / 2016$ & $\begin{array}{l}\text { MCNEIL \& DRUGS } \\
\text { Pharmaceuticals Ltd. }\end{array}$ \\
\hline
\end{tabular}

concentration of drug in the blood. After the serial dilutions to $10^{-2}$, the drug solution mixed with the blood was incubated at normal body temperature $\left(37^{\circ} \mathrm{C}\right)$ to facilitate drug-blood interactions (this is an in vitro experiment). The knowledge of the onset and duration of action of each drug was used in administering the start dose and the maintenance dose in the blood samples. These collected samples with drug concentrations were loaded into a centrifugal separator and the blood components were separated at Tahilah Diagnostic Laboratories, Awka. This helped to obtain such components as White Blood Cells (WBC) also called the Lymphocytes, Red Blood Cells (RBC), and the Plasma or Serum, each sample at a time. Glass slides were prepared and smeared with the samples for absorbance measurements. The slide preparations and sample smearing were done at the same laboratory. About 600 slides were successfully prepared in the laboratory.

\subsection{Measurements}

Absorbance measurements were done on all the different components of thirty samples (HIV infected blood of ones that had not started ARV treatment, HIV infected blood of those that had started ARV treatment and uninfected blood samples). A digital Ultraviolet Visible MetaSpecAE1405031Pro Spectrophotometer was used at the laboratory of the Department of Mechanical Engineering, Nnamdi Azikiwe University, Awka for the measurements. The absorbance values of the samples were measured over a range of wavelength between 230 and 800 Hertz alongside with their corresponding transmittance values. 


\section{Results and Discussion}

\subsection{The Absorbance values}

The absorbance values for each drug were plotted as a function of the wavelength as given in Figure 2.

\subsubsection{Antiretroviral Drugs in Air}

The absorbance was found to exhibit a peak at 320 for the first four drugs and at 290 for the fifth drug. The absorbance ranged from 0.398 for drug five to 1.2 for drug 4 (see Table 2)

Table 2 shows the peak absorbance values of different antiretroviral drugs in air ranging from 0.398 and 1.200 and their corresponding peak wavelengths range from 290 and 320 Angstrom. This falls within the visible range of the ultraviolet radiation which is 300 - 600 Angstrom.

\subsubsection{Infected Persons That Had Already Commenced Treatment with Antiretroviral Drugs}

The absorbance values measured for each of the ten samples were averaged; it was the average values for each blood component incubated in each antiretroviral drug for those that had previously started drug treatment that were plotted as a function of the wavelength, as given in Figure 3.

Figure 3 gives the absorbance results for drugs 1 to 5 in the HIV positive blood components with prior treatment with antiretroviral drug. The absorbance of the interacting systems significantly increased as the wavelengths increased until a peak absorbance was reached at $320 \AA$ for the Lymphocytes and Plasma, and $410 \AA$ for the Red blood cells and the Whole blood. Further increase in the wavelength gave rise to a decrease in the absorbance values which became almost constant between wavelengths 600 and $800 \AA$. The peak values fall within the visible range of the ultraviolet radiation. The peak absorbance values are presented in Table 3 together with the corresponding wavelengths.

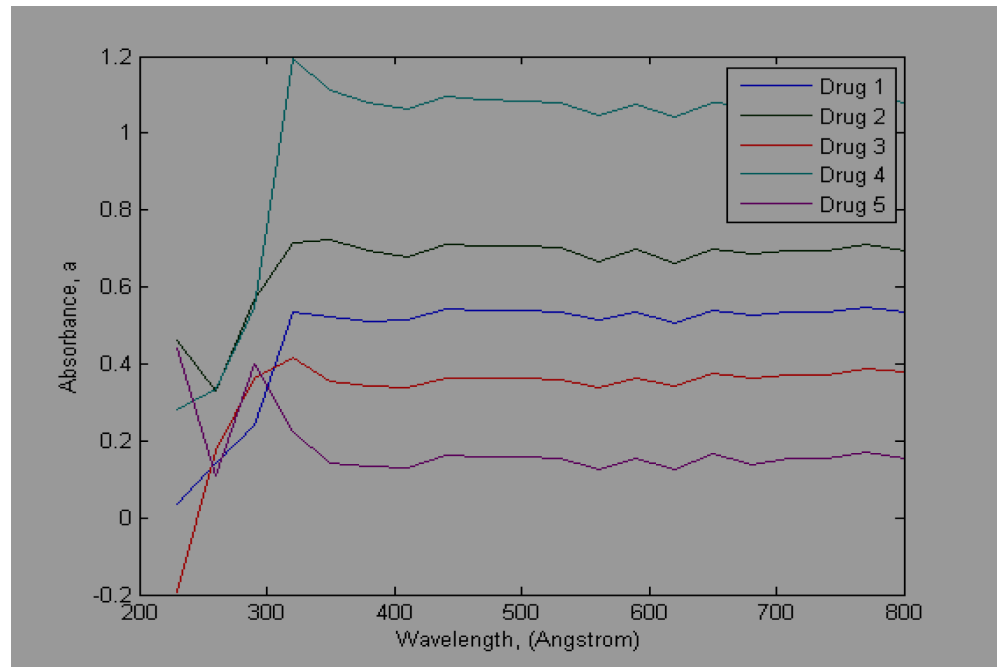

Figure 2. The relationship between Absorbance $a$ and Wavelength, $\lambda$ for the antiretroviral drugs alone.

Table 2. The Peak Absorbance values of different antiretroviral drugs in water with their Wavelengths.

\begin{tabular}{|c|c|c|}
\hline Drug Number & $\begin{array}{c}\text { Wavelength } \lambda(\AA) \\
\text { (Peak Values) }\end{array}$ & Absorbance, $\bar{\alpha}$ (Peak Values) \\
\hline D1 & 320 & 0.525 \\
\hline D2 & 320 & 0.722 \\
\hline D3 & 320 & 0.400 \\
\hline D4 & 320 & 1.200 \\
\hline D5 & 290 & 0.398 \\
\hline
\end{tabular}




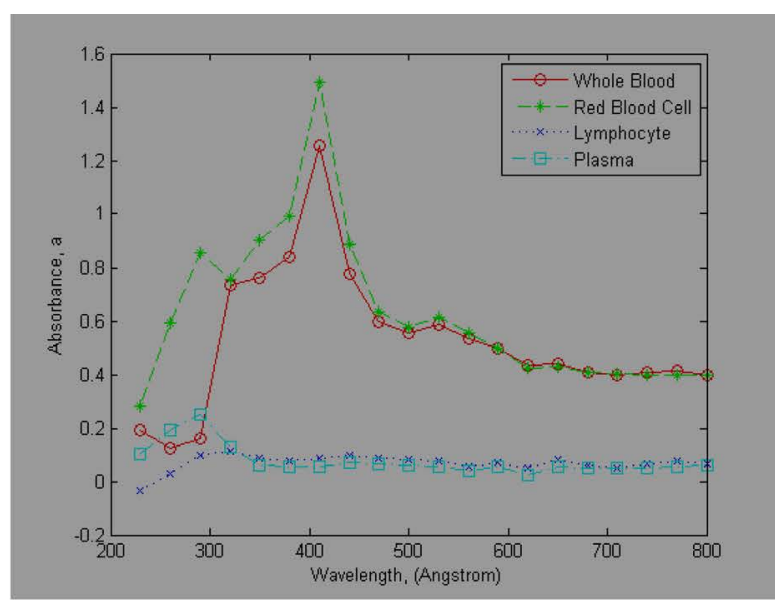

(a)

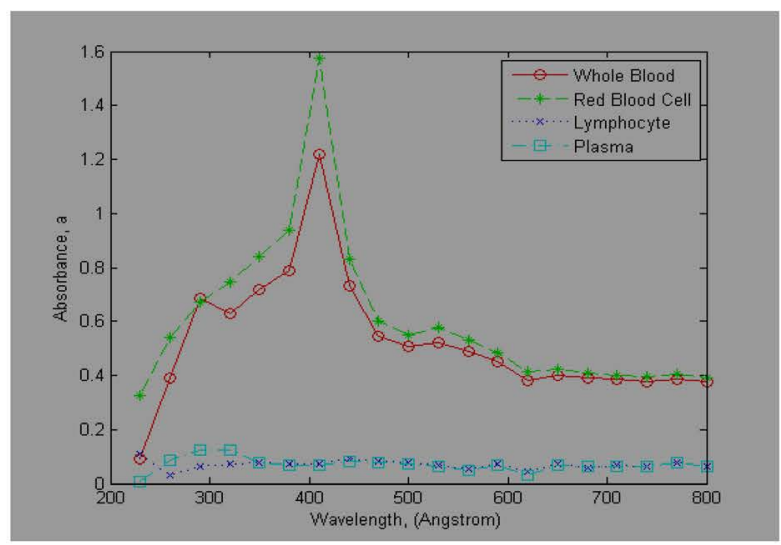

(c)

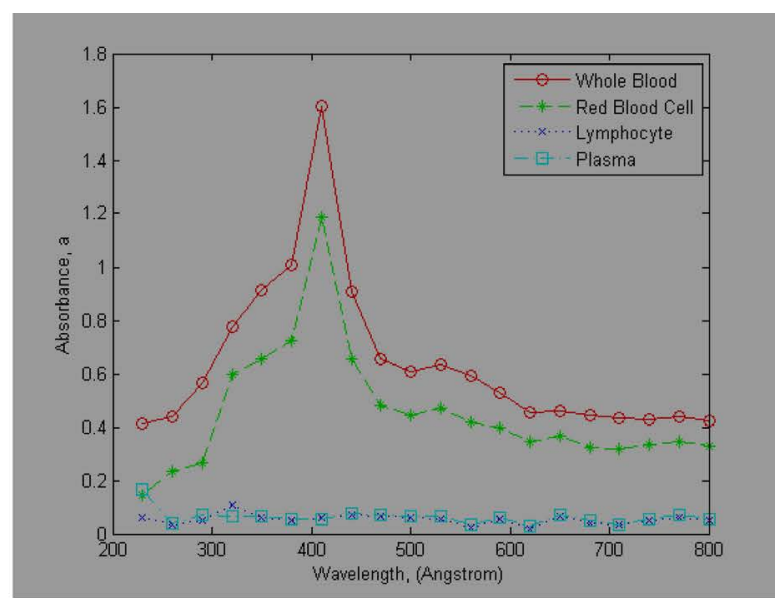

(b)

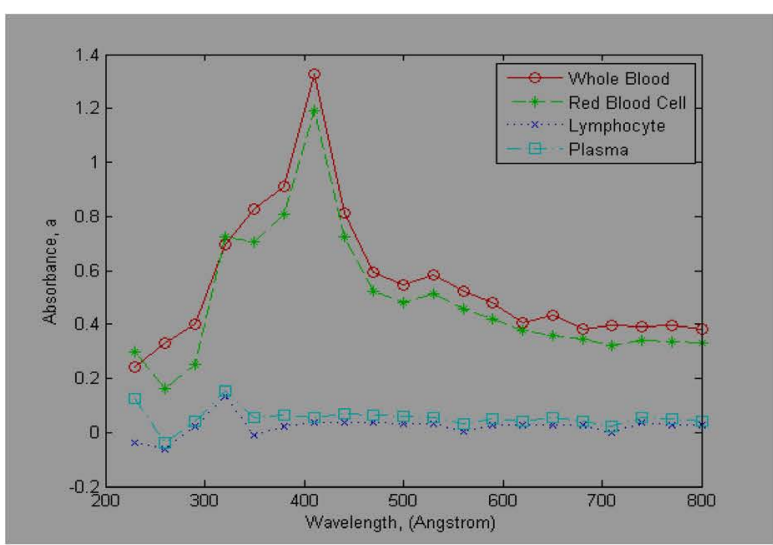

(d)

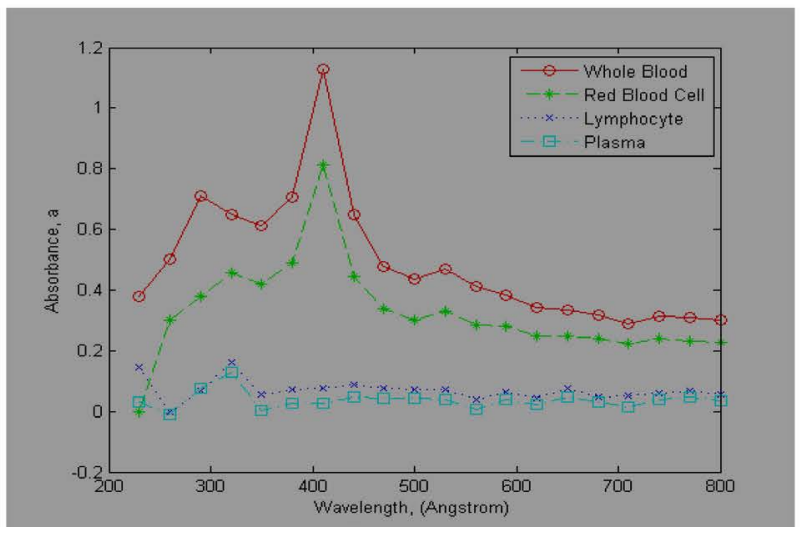

(e)

Figure 3. Absorbance, $a$ versus Wavelength, $\lambda$ for HIV Positive Blood of patients that had commenced antiretroviral drug treatment before this study. (a)-(e) Drug 1-5.

The peak absorbance values for the five antiretroviral drugs on Lymphocytes range from 0.08 to 0.18 , on Plasma they range from 0.08 to 0.20 , on Red blood cells they range from 0.80 to 1.58 , and on Whole blood they range from 1.17 to 1.60 .

\subsubsection{HIV Infected Persons Who Were Not Yet on HIV Drugs}

The absorbance values measured for each of the ten samples were averaged; it was the average values for each blood component incubated in each antiretroviral drug for those that had not previously started drug treatment 
that were plotted as a function of the wavelength, are given in the preceding Figure 4.

Figure 4 gives the results for drugs 1 to 5 in the HIV positive blood components of patients that had not commenced antiretroviral treatment before this study. As observed before, the absorbance values significantly increased as the wavelengths increased until a peak absorbance was attained. Further increase in the wavelength gave sharp decrease in the absorbance values which remained almost constant between wavelengths 600 and $800 \AA$. The peak absorbance values for the five antiretroviral drugs on Lymphocytes range from 0.18 to 0.30 , on the Plasma they range from 0.08 to 0.28 , on Red blood cells they range from 0.60 to 2.10 , on Whole blood they range from 1.00 to 1.40 , falling within the visible range of the ultraviolet radiation which is $300-600 \AA$; these values are presented in Table 4.

\subsubsection{HIV Negative Persons}

The absorbance values measured for each of the ten samples were averaged; it was the average values for each blood component incubated in each antiretroviral drug for HIV negative patients that were plotted as a function of the wavelength as given by [4]. The peak absorbance values from the work of Ani [4] are listed in Table 5.

Figure 5 gives the results for drugs 1 to 5 in the HIV negative blood components. As observed before, theabsorbance values significantly increased as the wavelenghts increased until a peak absorbance was attained. Further increase in the wavelength gave sharp decrease in the absorbance values which remained almost constant between wavelenghts 600 and $800 \AA$. The peak absorbance values for the five antiretroviral drugs on Lymphocytes range from 0.27 to 0.52 , on the Plasma they range from 0.18 to 0.30 , on Red blood cells they range from 1.05 to 1.40 , on Whole blood they range from 1.05 to 1.40 , falling within the visible range of the ultraviolet radiation which is $300-600 \AA$; these values are presented in Table 5.

Table 3. Data for absorbance for blood components of patients on drug treatment before this test.

\begin{tabular}{cccccccccc}
\hline Drug No. & \multicolumn{2}{c}{ Whole blood } & \multicolumn{2}{c}{ RBC } & \multicolumn{2}{c}{ WBC } & \multicolumn{2}{c}{ Plasma } \\
& $\lambda, \AA$ & $a$ (Peak) & $\lambda, \AA$ & $a$ (peak) & $\lambda, \AA$ & $a$ (peak) & $\lambda, \AA$ & $a($ Peak) \\
\hline 1 & 410 & 1.25 & 410 & 1.50 & 320 & 0.14 & 320 & 0.20 \\
2 & 410 & 1.60 & 410 & 1.20 & 320 & 0.10 & 320 & 0.08 \\
3 & 410 & 1.20 & 410 & 1.58 & 320 & 0.08 & 320 & 0.12 \\
4 & 410 & 1.36 & 410 & 1.20 & 320 & 0.17 & 320 & 0.18 \\
5 & 410 & 1.17 & 410 & 0.80 & 320 & 0.18 & 320 & 0.16 \\
\hline
\end{tabular}

Table 4. Absorbance data for blood components of patients not on drug treatment before this test.

\begin{tabular}{cccccccccc}
\hline Drug No. & \multicolumn{2}{c}{ Whole blood } & \multicolumn{2}{c}{ RBC } & \multicolumn{2}{c}{ WBC } & \multicolumn{2}{c}{ Plasma } \\
\hline & $\lambda, \AA$ & $\boldsymbol{a}$ (Peak) & $\lambda, \AA$ & $\boldsymbol{a}$ (Peak) & $\lambda, \AA$ & $\boldsymbol{a}$ (Peak) & $\lambda, \AA$ & $\boldsymbol{a}$ (Peak) \\
\hline 1 & 410 & 1.20 & 410 & 1.60 & 320 & 0.18 & 320 & 0.16 \\
2 & 410 & 1.36 & 410 & 1.76 & 320 & 0.26 & 320 & 0.08 \\
3 & 410 & 1.00 & 410 & 2.10 & 320 & 0.20 & 320 & 0.19 \\
4 & 410 & 1.40 & 410 & 2.08 & 320 & 0.30 & 320 & 0.28 \\
5 & 410 & 1.36 & 410 & 1.70 & 320 & 0.19 & 320 & 0.20 \\
\hline
\end{tabular}

Table 5. Data for absorbance for blood components of patients that were HIV negative.

\begin{tabular}{|c|c|c|c|c|c|c|c|c|}
\hline \multirow[t]{2}{*}{ Drug No. } & \multicolumn{2}{|c|}{ Whole blood } & \multicolumn{2}{|c|}{ RBC } & \multicolumn{2}{|c|}{ WBC } & \multicolumn{2}{|c|}{ Plasma } \\
\hline & $\lambda, \AA$ & $a$ (Peak) & $\lambda, \AA$ & $a$ (Peak) & $\lambda, \AA$ & $a$ (peak) & $\lambda, \AA$ & $a$ (Peak) \\
\hline 1 & 410 & 1.05 & 410 & 1.50 & 320 & 0.48 & 320 & 0.22 \\
\hline 2 & 410 & 1.40 & 410 & 1.88 & 320 & 0.52 & 320 & 0.18 \\
\hline 3 & 410 & 1.20 & 410 & 1.90 & 320 & 0.30 & 320 & 0.26 \\
\hline 4 & 410 & 1.24 & 410 & 2.28 & 320 & 0.28 & 320 & 0.30 \\
\hline 5 & 410 & 1.38 & 410 & 2.18 & 320 & 0.27 & 320 & 0.20 \\
\hline
\end{tabular}




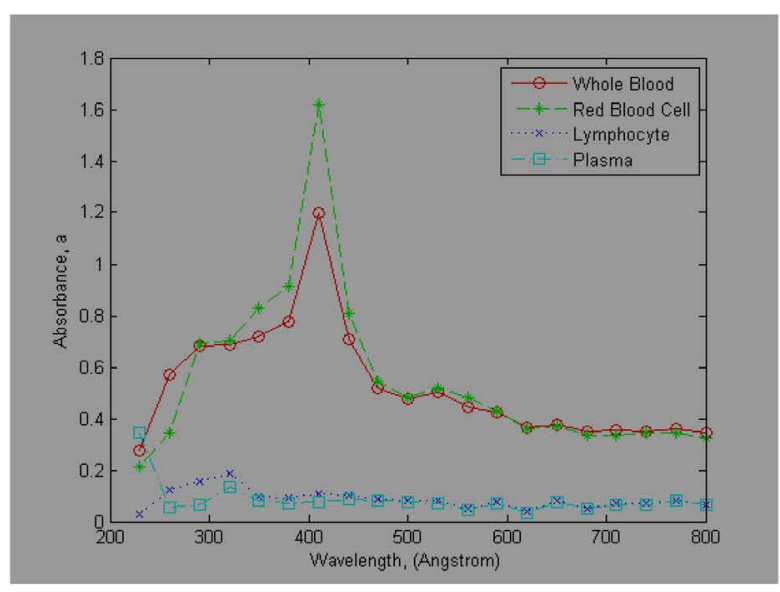

(a)

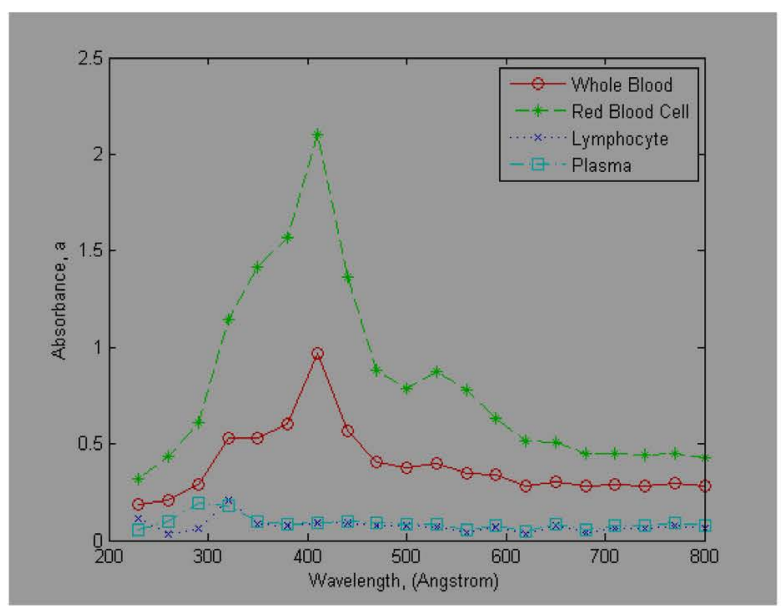

(c)

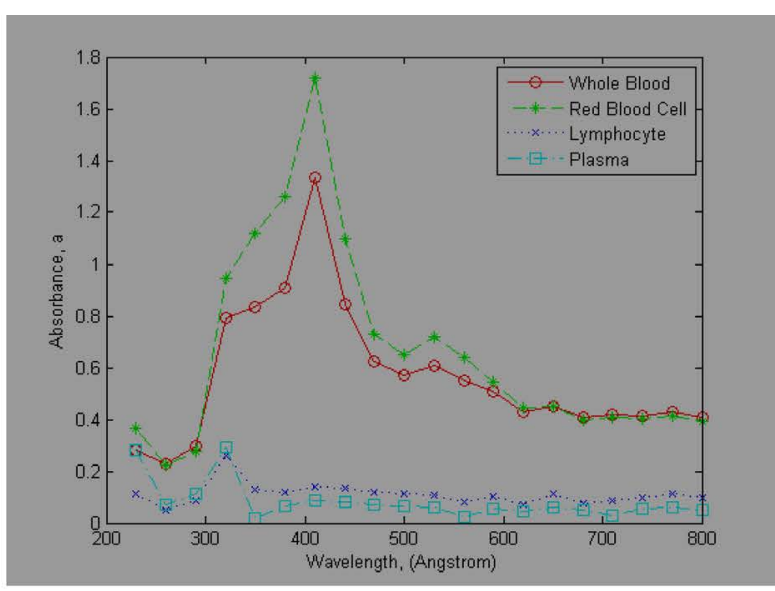

(b)

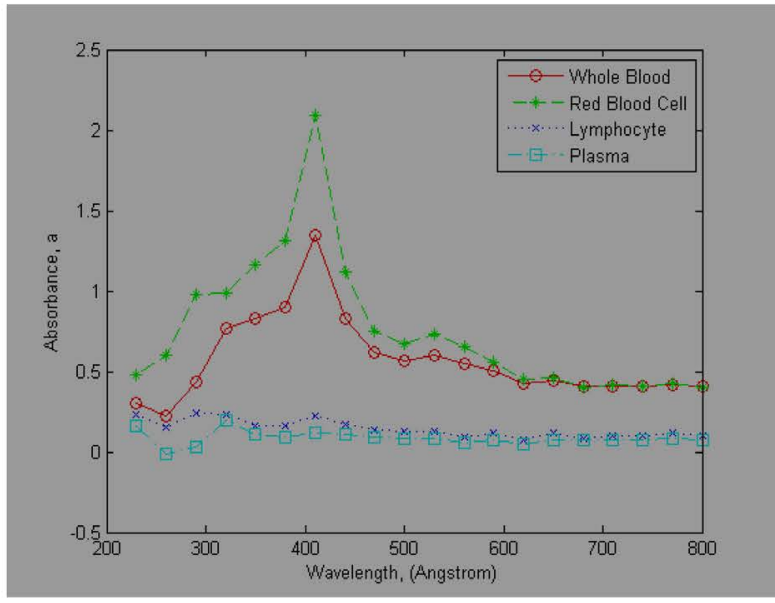

(d)

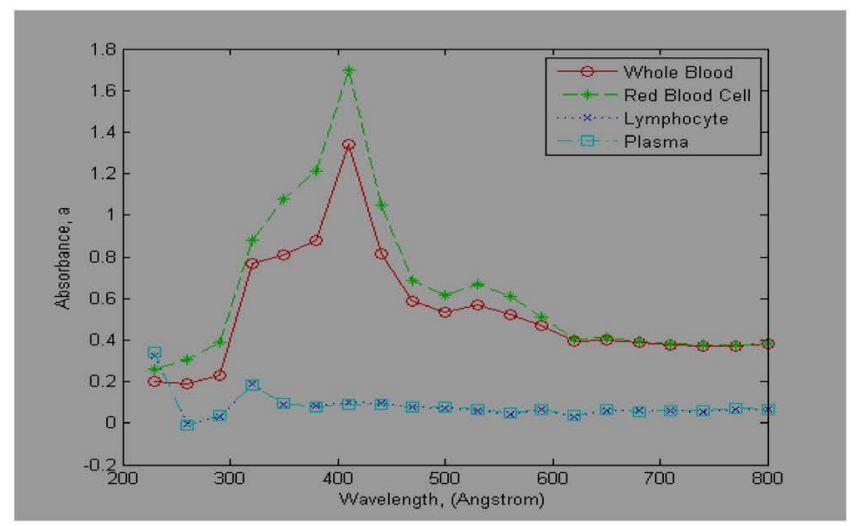

(e)

Figure 4. Absorbance, $a$ versus Wavelength, $\lambda$ for HIV positive blood components of patients that had not previously commenced antiretroviral drug treatment. (a)-(e) Drug 1-5.

Table 5 gives the data for absorbance for blood components of patients that were HIV negative. The peak absorbance values of the blood components with antiretroviral drugs are higher than the peak absorbance values of the blood components without antiretroviral drugs when Table 4 is compared with Table 2 and Table 3 . This indicates that the antiretroviral drug has the effect of increasing the peak absorbance values of the blood components, i.e., the drugs are made able to increase the light absorption capacity of the blood cells. Previous researches Achebe [1] have shown that the virus reduces the peak absorbance values of the blood components. 


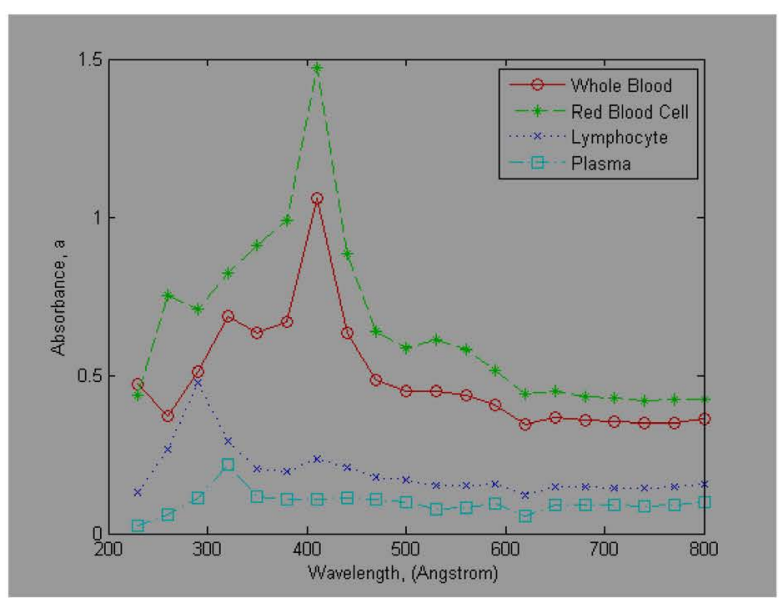

(a)

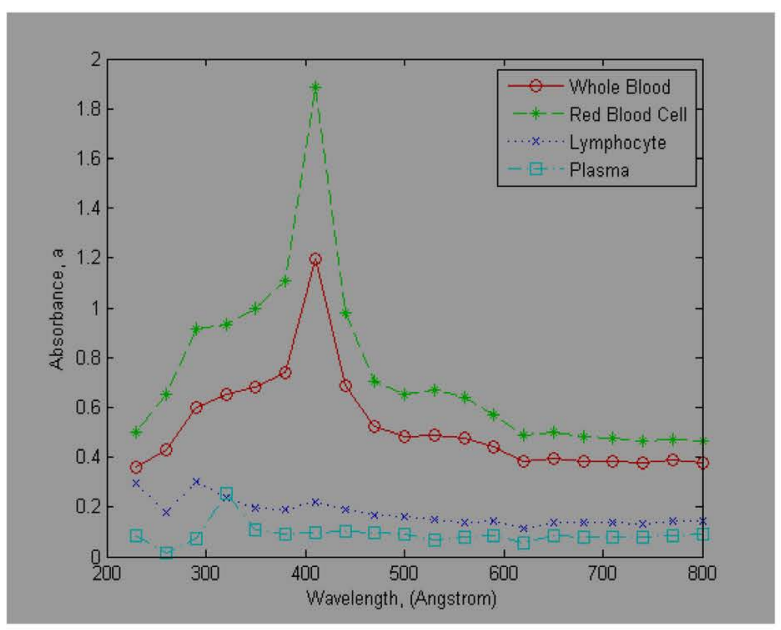

(c)

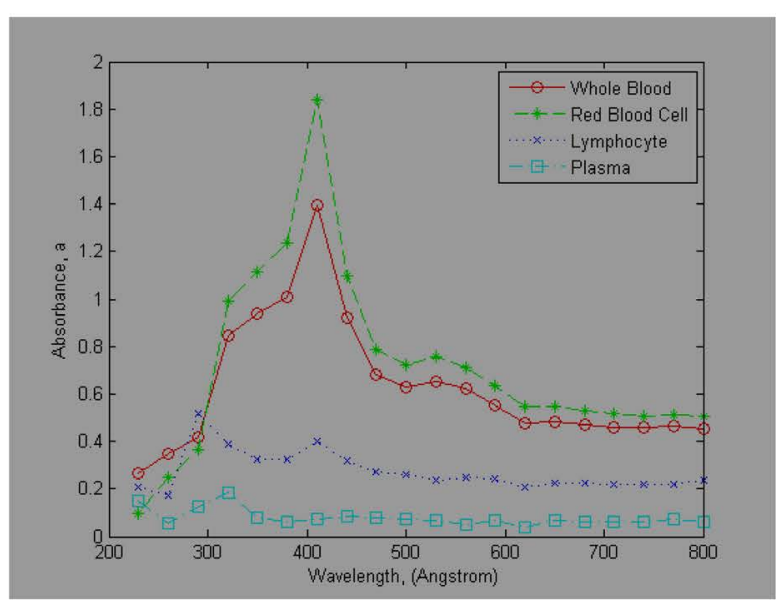

(b)

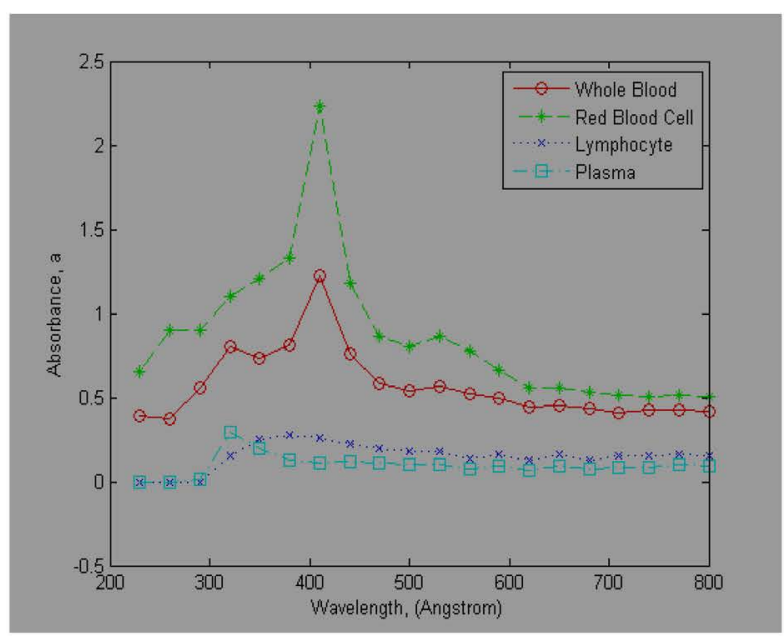

(d)

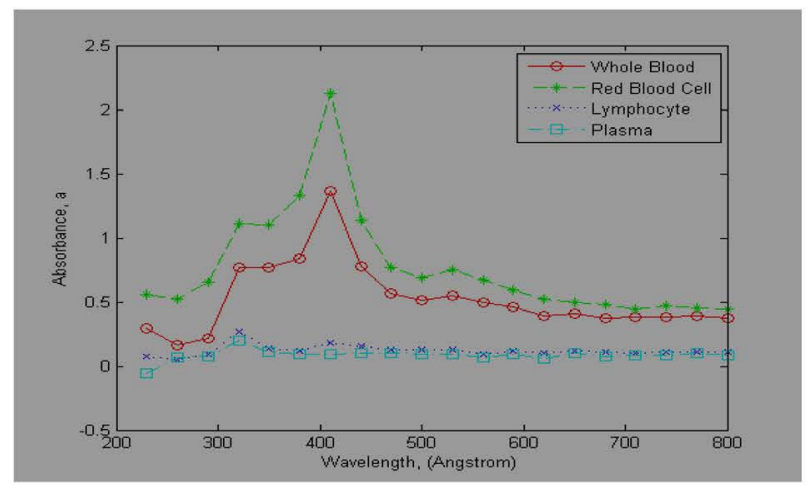

(e)

Figure 5. Absorbance, $a ́$ versus Wavelength, $\lambda$ for for HIV negative blood components. (a)-(e) Drug 1-5.

Table 6. Peak absorbance data for WBC for the three scenarios (ABC).

\begin{tabular}{ccccccc}
\hline & The Scenarios & Drug 1 & Drug 2 & Drug 3 & Drug 4 & Drug 5 \\
\hline A & HIV + ve with Drug Pretreatment & 0.14 & 0.10 & 0.08 & 0.17 & 0.18 \\
B & HIV + ve without Drug Pretreatment & 0.18 & 0.26 & 0.20 & 0.30 & 0.19 \\
C & HIV - ve & 0.48 & 0.52 & 0.30 & 0.28 & 0.27 \\
\hline
\end{tabular}


This work compared the peak absorbance values of HIV positive blood and HIV negative blood and reported that the absorbance values of uninfected blood components were higher than those of infected blood components. The absorbance values of HIV positive samples are generally decreased by a significant factor. The apparent decrease in the absorbance of the HIV infected blood samples reveals the role of the virus in significantly affecting the surface properties of the infected blood cells [5]. It was also reported by Ozoihu [6] that HIV has the capacity to reduce the surface energy of blood. However, the restorative action of antiretroviral drugs is a positive sign to the reduction of the virus effect. This work is devoted to showing that the surface property of a blood component can be significantly changed by the antiretroviral drugs and that this effect can possibly be used in drug design.

\subsubsection{Test of Significance}

We study further the variation of peak absorbance between the three scenarios under consideration, for WBC which is the target for HIV, as extracted from Tables 2-4 and listed in Table 6.

The analysis of variance (ANOVA) for the three data sets gives the computed $\mathrm{F}$ ratio as 11.19 which is higher than the critical $\mathrm{F}$ ratio 3.88 for 0.05 level of significance. This shows that there are significant differences between the scenarios, A, B and C. To identify the scenario that is most significant analyses of the means of the data of Table 5 become necessary. Between scenarios A and $\mathrm{B}$, the computed $\mathrm{F}$ ratio is 3.35 which is less than the critical $\mathrm{F}$ ratio of 4.75 . This shows that there is no significant difference between scenarios $\mathrm{A}$ and $\mathrm{B}$. Analyses of $\mathrm{B}$ and $\mathrm{C}$, and of $\mathrm{A}$ and $\mathrm{C}$ show there are significant differences between these pairs. These results show that scenario $\mathrm{C}$, the absorbance of HIV negative white blood cells, is most significant. Thus, the light absorption capacities of the surfaces of the HIV negative white blood cells are higher than the light absorption capacities of HIV positive WBC whether or not they had earlier been subjected to antiretroviral drug treatment or not.

\section{Conclusion}

In the twenty first century's research works, there may be a need to achieve a more reliable research result through a synergy between engineers and biological researchers. The peak absorbance data for various interacting systems were measured. These were used to show that the antiretroviral drug had the effect of increasing the peak absorbance values of both the uninfected and infected blood components, i.e., the drugs were made able to increase the light absorption capacity of the blood cells. The use of the findings of this work by pharmaceutical industries may help in the search for more effective antiretroviral drugs for the treatment of HIV patients.

\section{References}

[1] Achebe, C.H. (2010) Human Immunodefficiency Virus (HIV)-Blood Interactions: Surface Thermodynamics Approach. Ph.D. Dissertation, Nnamdi Azikiwe University, Awka.

[2] United States Department of Health and Human Services (2004) A Guide to Primary Care for People with HIV/AIDS. 2004 Edition.

[3] Achebe, C.H. and Omenyi, S.N. (2013) The Effects of Human Immunodeficiency Virus (HIV) Infections on the Absorbance Characteristics of Different Blood Components. International Journal of Engineering and Science Invention, 2, 53-61. www.ijesi.org

[4] Ani, O.I. (2015) Surface Energetics Study of the Interactions between HIV and Blood Cells Treated with Antiretroviral Drugs. Ph.D. Dissertation, Nnamdi Azikiwe University, Awka.

[5] Achebe, C.H. and Omenyi, S.N. (2013) The Application of Negative Hamaker Concept to the Human Immunodeficiency Virus (HIV)-Blood Interactions Mechanism. In: Yang, G.-C., Ao, S.-L. and Gelman, L., Eds., Transactions on Engineering Technologies-Special Volume of the World Congress on Engineering 2013, Springer, Berlin, 281-293. http://dx.doi.org/10.1007/978-94-017-8832-8_21

[6] Ozoihu, E.M. (2014) Human Immunodefficiency Virus (HIV)-Blood Interactions: Contact Angle Approach. Ph.D. Dissertation, Nnamdi Azikiwe University, Awka. 